\title{
Exploring common stressors in physical education: a qualitative study
}

Kate Tudor

School of Sport, Exercise and Health Sciences, Loughborough University, UK

Mustafa Sarkar

School of Science and Technology, Nottingham Trent University, UK

Christopher M. Spray

School of Sport, Exercise and Health Sciences, Loughborough University, UK 


\section{Abstract}

Daily stressors, or hassles, refer to the everyday environmental demands that constitute a threat or challenge, or exceed an individual's biological or psychological capacities (Cohen et al., 1995). Increasing evidence suggests that daily stressors have a significant impact on adolescents' educational outcomes, for example, performance, wellbeing and negative attitudes toward school, however there is limited research examining the concept of common stressors in PE lessons. As early-adolescence is a developmental period associated with decreased engagement in PE, it is important to identify the environmental stressors that may be associated with increased disengagement. The study comprised 54 secondary school students and six PE teachers from five schools in the English Midlands. Semi-structured focus groups were conducted and a thematic analysis was applied to interview transcripts. Three higher order themes were identified from the data: the social environment, the physical and organisational environment, and the performance environment. Common stressors within the social environment included, interpersonal transactions between peers, differences in effort levels during PE, and working outside one's peer group. Stressors within the physical and organisational environment consisted of, environmental situations within the changing facilities and the availability of activities. Finally, performance environment stressors included, situations involving the difficult acquisition of physical skills, and situations where physical appearance and physical competencies were exposed. The study extends previous findings by identifying potentially threatening and frustrating, environmental demands that have not been identified in the previous literature. The current study is the first to explore the typical stressors that are experienced by students in PE. 


\section{Introduction}

There is strong evidence that physical activity helps to prevent a number of chronic health conditions (O’Donovan et al., 2010) and inactivity is a major risk factor for premature mortality (Kohl et al., 2012). Evidence suggests that levels of physical activity, specifically moderate-to-vigorous intensity physical activity (MVPA), decline during adolescence (Armstrong and Welsman, 2006; Corder et al., 2015). School physical education (PE) provides a context for regular and stuctured physical activity particiption; however evidence suggests that in many PE lessons, students do not engage in sufficient MVPA to achieve health benefits (Hollis et al., 2017; Lonsdale et al., 2013). Educational researchers have sought to understand why students are not engaging in sufficient levels of MVPA, identifying a combination of factors including: enjoyment or interest (Jaakkola et al., 2017), physical self-concept (Babic et al., 2014), perceived competence (Fairclough, 2003), teaching approach and environment (Grắstén, 2016), and self-determined motivation (Aelterman et al., 2012; Mitchell et al., 2013; Standage et al., 2005).

While the identification of predominantly cognitive factors has contributed to understanding of what promotes active participation in PE, previous findings do not explain the total variance of students' active participation in lessons. One concept that has been studied within educational psychology is how the incidence of everyday academic stressors (and how students respond to such stressors) can predict motivational and engagement outcomes (Martin, 2013; Martin and Marsh, 2008). There has been limited research on the incidence of everyday, or common, stressors associated with PE and students' ability to deal effectively with such stressors. Given the importance of 
cumulative, minor stressors on academic outcomes, identifying the stressors that students typically experience in their PE lessons may help explain patterns of motivation and engagement in the subject.

\section{The experience and impact of daily stressors in adolescence}

Early research defined the concept of psychological stress in one of two ways: as a stimulus (or 'stressor', focusing on events within the environment), or a response (focusing on the state of stress). However, it was soon established that individual differences mediated the relationship between stressors and one's response to these stressors (Lazarus and Eriksen, 1952; Lazarus and Launier, 1978; Lazarus and Folkman, 1984). Thus, psychological stress is viewed as a transactional process, and defined as the relationship between the person and the environment that is appraised by the individual as taxing, or exceeding resources and endangering wellbeing (Cohen, Kessler, and Gordon, 1995; Lazarus and Folkman, 1984).

Stressors are defined as the "experiences of daily living that have been appraised as salient and harmful or threatening to the endorser's wellbeing" (Lazarus and Folkman, 1984, p 376). Importantly, stressors are viewed as environmental stimuli, meaning that two individuals may have a different psychological response to the same stressor. The stressors that children experience can be categorized into: life events, chronic stressors, and daily stressors (or everyday hassles). Life events constitute those exceptional, traumatic circumstances that require significant adjustment, for example, the death of a family member or parental divorce (Williamson et al., 2003). Chronic stressors are the harsh and ongoing physical or social conditions associated with disadvantage, for example, poverty or disability (Evans, 2006; Serido et al., 2004) Finally, daily stressors, 
or everyday hassles, are the irritating demands that characterize frequent transactions between an individual and their environment (Kanner, Coyne, Schaefer, and Lazarus, 1981). These hassles may include practical problems (e.g. losing things) or fortuitous occurrences (e.g. arguments or disappointments; Kanner et al., 1981).

It has become increasingly evident that everyday environmental demands may form the primary cause of the stress experience in children (Byrne et al., 2011; Compas, 1987; Kearney et al., 1993; Kraag et al., 2006; McNamara, 2000). For children, everyday stressors relate to health, family, school and peers (Kanner, Feldmen, Weinberger, and Ford, 1987). In school, achievement demands (e.g. not attaining expected grades or giving public performances), interpersonal relationships (e.g. with teachers and peers), and general school disrupters (e.g. class size) have been identified as sources of stress (Bauwens et al., 1989; Grannis, 1992; Kanner et al., 1987). More recently, research has found that most children reported multiple daily stressors at school, including interpersonal conflict and the demands of mastering new topics. Moreover, stressor experience in one area of school life impacted the stress response reported in other aspects of school on the same day (Sotardi, 2017).

Increasing evidence suggests that daily stressors have a significant impact on various outcomes, due to their cumulative and proximal nature. Adolescents' experience of daily stressors has been associated with anxiety (Carter et al., 2006; Kiang and Buchman, 2014), depression (Band and Weisz, 1990), low self-esteem (Escobar et al., 2013; Sandstrom et al., 2003), emotional wellbeing (Kiang and Buchman, 2014), antisocial behaviour (Sim, 2000), and negative interactions with parents (Lehman and Repetti, 2007). Moreover, daily stressors have been shown to be related to decreased 
attentional control (Liston et al., 2006), and cognitive performance (Rahdar and Galvan, 2014), which some scholars suggest may manifest as negative attitudes towards school and decreased academic achievement (Byrne et al., 2011; Torres et al., 2012).

Research exploring daily stressors in adolescence has focused primarily on academic demands, with little emphasis of the influence of potential stressors in PE (Barrett and Heubeck, 2000; Heubeck and O’Sullivan, 1998). However, researchers have begun to explore the perceived barriers to physical activity and students' participation in PE lessons. Elliott and Hoyle (2014) suggested that wearing a particular PE kit led to self-consciousness in female students, and O'Connor and Graber (2014) highlighted the increased tendency for bullying in PE, predominantly ignited by body image, attire, and physical ability. Furthermore, the public and competitive nature of PE compared to other classroom-based subjects may lead to greater concern with regards to ability and performance (Yli-Piipari et al., 2009). Ridgers, Fazey, and Fairclough (2007) reported that perceived physical competence was associated with the degree of apprehension students' experienced at the prospect of being negatively evaluated in PE.

Researchers have also highlighted the unique context that students are placed in during their PE lessons. PE represents one of the most significant contexts in which body image and physical self-perceptions impact on student experience (Fox and Edmunds, 2000). Indeed, PE is an environment whereby "the body is explicitly used, displayed and talked about" (Paechter, 2003 p. 49) and research has identified body image issues as a psychological barrier to PE participation. Moreover, Wiltshire, Lee, and Evans (2017) explored the role of adolescents' 'physical capital' in PE, finding that students were concerned about the immediate social risks of being overweight or obese. At present, 
however, there is no systematic knowledge regarding the range of daily, or common, stressors that the majority of students' experience in PE.

Daily stressors are distinct from many of the examples reported above, which are often termed by authors as 'barriers'. Barriers, by definition, are circumstances or obstacles that keep things apart or that prevent the advance of persons or things (New Oxford Dictionary of English, 2010). This definition assumes that all environmental situations have an equally obstructive impact on all students that experience them. Moreover, the term barrier is often used by authors to represent a cognitive appraisal of an environmental stimulus (i.e. a 'psychological barrier', such as self-consciousness). In contrast, stressors in PE are the environmental stimuli experienced by the majority of students that may or may not be appraised as salient or threatening. The term barrier is used inconsistently, and is not explicitly defined in existing literature (Elliott and Hoyle, 2014), and does not effectively encompass the range of environmental situations that are experienced by the majority of students. The current study therefore seeks to explore the common and potentially stressful events or situations that are experienced in secondary school PE lessons. The study utilized Lazarus' (1984) definition of daily stressors, that is, “experiences of daily living that have been appraised as salient and harmful or threatening to the endorser's wellbeing" ( $p$ 376). Thus, the focus was not to explore students' emotional responses or appraisals, but specifically on exploring specific environmental stimuli that have the potential to be negatively appraised.

\section{Method}

\section{Participants}


Participants included 54 students $($ male $=21$; female $=33)$ aged between 11 and 16 $(M=13.0, S D=1.14)$, and six PE teachers (male: four; female: two), with a range of two to 12 years teaching experience $(\mathrm{M}=7.2, \mathrm{SD}=3.70)$. Participants were recruited from five secondary schools in the Midlands of England. The five schools were all comprehensive schools and all mixed gender. Schools consisted of a range of socio-economic status (i.e. four schools had below average number of students who were eligible for free school meals whilst one school had above average). All of the recruited schools had a majority of White British students. In the current study, the sample consisted of participants who could best represent the topic of stressors in PE (i.e. students and teachers from schools located in both affluent and socioeconomically deprived areas). Pseudonyms are used within the text which enables the participants' identities to remain anonymous.

\section{Design and procedure}

The present study was conducted within the interpretivist paradigm, which aims to understand the complex world of lived experience from the point of view of those who are living it (Schwandt, 1998). The approach is underpinned by relativist ontology, positing that there is no single external reality, and reality is constructed through language and shared meanings. Moreover, the interpretivist approach is underpinned by a subjectivist epistemology, where there is a clear link between the researcher and participant, and findings are the creation of the interaction between the researcher and participant (Guba, 1990).

After obtaining ethical clearance from the ethics committee of a British university, participants were recruited by writing to the head-teacher, explaining the study, and requesting to conduct focus groups with a sample of students, and interviews 
with PE teachers. If the head-teacher agreed and consent was granted, PE teachers were contacted by the lead researcher, explaining the details of the study. Focus groups were conducted with students, and interviews were conducted with teachers. All of the interviews were recorded using a dictaphone, and the head author recorded notes regarding the answers provided.

\section{Student focus groups}

Teachers were instructed to select five or six students to form each focus group, who ranged in physical ability and engagement in PE. Each focus group consisted of students from the same class (therefore the same age and gender). Focus groups were chosen as they are proposed to be appropriate for situations where research is aiming to draw upon participants' beliefs, attitudes, and feelings by exploiting group processes (Ennis and Chen, 2012). Moreover, the focus group approach was made in an attempt to reduce the adult/child power relationship that may be a disruptive element in one-to-one interviews. Construction of focus groups with participants of the same age and gender was designed to facilitate an environment whereby students felt comfortable (Ennis and Chen, 2012).

An interview guide was constructed to ensure that questions were focused on the topic under investigation, which was broadly focused on exploring students' experiences of stressors in PE. Interview guides were piloted on secondary school students to test question comprehension, particularly to identify child-friendly terms for the construct of daily stressors. Following piloting, the guides were altered to make questions more coherent for participants. The interview guides consisted of a brief introduction on the concept of daily stressors, followed by open-ended questions. All focus groups were 
conducted during students' scheduled PE lessons by the lead author. There are various interpretations, expectations, or quality assurances with regards to the concept of data saturation in qualitative research studies (see, for a discussion, O'Reilly and Parker, 2013). In the current study, due to logistical reasons (i.e. collecting data during scheduled PE lessons) the focus groups were limited to one hour each, and ranged from 35 to 55 minutes. Despite this, it was felt that each focus group was conducted to a point at which all questions were explored in detail and the experiences of all participants were captured (Morse, 2003; O’Reilly and Parker, 2013). Each focus group was audio-recorded and transcribed verbatim (producing 226 pages of single-spaces transcribed text). The analysis of each focus group prior to further data collection was conducted to ensure that all potential themes were thoroughly explored.

\section{Teacher interviews}

A second interview guide was developed to ensure that questions in the interviews with teachers were focused on the topic under investigation. Questions in this interview guide were similar in content to the interview guide for the focus groups, however, some wording was changed to meet differences in student and teacher comprehension levels. The interview guide was not piloted on teachers, however was reviewed by PE teachers working within the university department prior to data collection. Interviews were conducted with PE teachers during their free time. Sample size cannot be pre-determined, given the need for a thorough exploration of an as yet unknown phenomenon (Morse, 2003); teacher interviews were held until a point where all questions were explored in detail and the wealth of experiences of students in PE were addressed. Using the same 
process described above (for focus groups), teacher interviews were audio recorded and transcribed verbatim (producing 60 pages of transcribed single-spaced text).

\section{Data analysis}

A thematic analysis technique was employed through both inductive (i.e. derived from the data) and deductive (i.e. derived from the conceptual framework of the study) analysis. The analysis followed a six-stage process; (1) familiarisation with the data through the manual transcription of interviews, (2) the generation of initial codes of salient features of the data, (3) identifying themes within the codes, (4) reviewing the themes, (5) defining the identified themes and (6) reporting the findings, extracting data that corresponds to the identified themes (Braun and Clarke, 2006; Clarke and Braun, 2013). A reflective diary to note the researcher's initial thoughts during data collection, was utilised to guide the analysis. The transcribed responses were collated into lower order themes, which could be represented by a number of data quotes. Further analyses resulted in the categorization of the lower order themes into higher order themes, and a further smaller number of general dimensions.

Data were analysed in an iterative process between data and theory, meaning that the transcripts were repeatedly returned to, to ensure that the findings were truly derived from the data. It is important, however, to acknowledge the active role of the researcher in identifying themes in thematic analysis. Specifically, during data analysis, researchers made decisions regarding the importance of the transcribed data and themes did not passively emerge from the data. Therefore, the themes reported should be considered a result of on-going interpretation of the authors (Braun and Clarke, 2006). 


\section{Methodological rigour}

To ensure the credibility and trustworthiness of the data, discussions took place within the research team during the analysis to ensure alternative interpretations of the data were considered (Smith, 2007). The first and third author coded $100 \%$ of the data. Discussion of the generated themes and the emerging categories were reviewed and refined so the findings could be considered credible and transferable (Lincoln and Guba, 1985). Some doubts and disagreements arose between the first and third author with regard to some coding and categorization into themes and subthemes. Specifically, there was discussion regarding whether a given situation in PE reported by students should be considered an event or the appraisal of an event. Consequently, the second author coded $25 \%$ of the data to a) ensure consistency in the interpretation of the data and b) address the disagreements between the first and third authors. In the cases of doubt, a discussion took place between all three authors until a majority consensus was reached (i.e. two authors were in agreement).

\section{Results and discussion}

The results derived from the thematic analysis procedures are a representation of participants' collated responses. Table 1 has been constructed to highlight higher order themes that showed clear links to lower order themes. The interview data yielded rawdata quotes comprised of 17 lower order themes and seven higher order themes. The higher order themes formed three general dimensions of stressors in PE: the social environment, the physical and organisational environment, and the performance environment. 


\section{Social environment}

Social environment consisted of two first-order themes: peers and teachers (see Table 1). With regards to peers, potential environmental stressors in PE ranged from situations whereby students worked outside their usual peer group, the existence of cliques related to ability, and interpersonal transactions between peers. In terms of teachers, some students reported teachers being strict, the enforcement of PE kit rules, and teachers' 'choice' of activities to be potentially demanding. The most frequently cited stressors in the higher order theme of the social environment were interpersonal transactions between peers.

Peers

Students recalled that being separated from their friends or being in a group with individuals they 'don't know' or 'don't get on with' as a potential stressor: 'you feel really uncomfortable when you're with no one that you really like or know... You're out of your comfort zone'. [Jess, year 10]. Relatedly, the students recalled sporty classmates working together which sometimes created a 'cliquey' atmosphere in lessons, which was supported by teachers reporting that the social capital associated with physical ability was often reflected in cliques within PE lessons. These findings support previous research identifying PE as a context whereby physical abilities can contribute to students' social capital, resulting in the formation of hierarchical social groups (Hills, 2007; Wiltshire et al., 2017), thus, teaching practices may be modified to facilitate more inclusive peer interactions.

Participants recalled interpersonal transactions between peers (i.e. comments that are made that have the potential to cause harm or upset), which were unique to the PE 
setting, most likely relating to a student's physical appearance or athletic ability. A group of year seven males discussed teasing in the changing rooms (see Table 1), openly discussing the negative impact of their own actions on other students. Similarly, girls discussed some students not getting involved during PE lessons due to the comments from their peers regarding physical appearance: 'There's some people that are like, quite conscious about their appearance... and that kind of stops them from getting involved... They think, "oh, what are they saying about me?"' (Joanna, year 8). Another potentially negative interaction between peers was the tendency for higher ability students to gloat about their superior physical ability. Furthermore, some female students recalled situations where male students boasted about their superior athletic ability, which was more apparent in mixed gender classes. While some girls appraised this as a tool to spur them on, others found it detrimental to participation.

Some students recalled situations whereby differences in PE participation were very apparent. Some students described not getting a chance to participate as a result of the higher ability students (for example, never being passed to). Previous research has highlighted the physical involvement and social acceptance that being passed to affords (Hills, 2007), and students in the current study stated that exclusion in this way resulted in the tendency to disengage from the game. In contrast, students with high perceived competence stated a tendency for lower ability students to 'just stand at the side' and let them do all the work. High ability students put their counterparts' lack of participation down to 'laziness' and 'not taking PE seriously', not considering that discrepancies in participation may stem from previous experiences of exclusion. 
Many of the findings related to interpersonal transactions between peers support previous literature, for example the increased tendency of teasing underpinned by appearance and ability (O’Connor and Graber, 2014). This finding extends previous research by identifying unique environmental situations that have not previously been highlighted in the literature as a potential source of harm or distress (e.g. boasting about ability levels and classmate effort of participation).

\section{Teachers}

Other social environmental stressors, that had the potential to be appraised as harmful, included transactions with teachers, however these were less frequent. Some students described situations whereby teachers being too strict could take the fun out of the PE experience. Moreover, some students found that being reprimanded for forgetting their PE kit, or wearing the incorrect uniform, to be a stressor for them. A male student recalled being consistently reprimanded for wearing the incorrect socks for his PE lessons, and could not understand why a small detail should be important. Female students also struggled to understand the importance of wearing a specific uniform, often expressing it was not warm enough in the winter months. Again, while such environmental stimuli may be appraised by some students as minor, their cumulative occurrence for some students may result in reduced or non-participation during lessons.

[Insert Table 1 here]

\section{Organisational and physical environment}

Organisational and physical environment was comprised of two higher-order themes: facilities and the availability and range of activities. The most frequently cited 
stressors within this dimension were those related to space and privacy within the changing rooms.

\section{Changing room facilities}

Some teachers and students suggested that the process of getting changed in school facilities to be a stressor that could be appraised as harmful by some students, due to overcrowding during the changeover of PE lessons: 'The year tens are all coming in when you're getting changed... and they try to put pressure on us and it really annoys us' [Emma, year eight]. Moreover, some teachers suggested that getting changed for some students resulted in strong anxiety symptoms, resulting in teachers' making arrangements for a small group to change in the staff changing rooms. These findings resonate with previous research identifying the changing room environment to be a potentially negative experience for students (Flintoff and Scraton, 2001). They also demonstrate the distinction between environmental stimuli that may result in a severe stress response in some students (i.e. anxiety symptoms resulting from changing with classmates), and those that result in a less severe stress response (i.e. feeling of frustration from being rushed to get changed). Both types of stressors that have the potential to cause disaffected responses may result in students leaving their kit at home, resulting in non-participation in lessons. While it is difficult for schools to provide the infrastructure to overcome these issues, teachers should pay careful attention to those students who may not be participating in PE lessons for this reason.

\section{Availability of activities}

Female students of all age groups recalled the activities available to them within the curriculum to be a source of frustration in PE. They recalled a gender difference in PE 
activities, demonstrated here by year 10 girls: 'Some sports just aren't available for girls... like football... rugby. People may enjoy those sports more than the normal girls' ones, like netball' (Sarah, year 10). Further, females reported being restricted in PE 'levels', demonstrated in Table 1, by participating in activities at a 'lower level' to their

male counterparts (e.g. touch rugby versus full contact rugby). Enjoyment and interest are associated with active participation in PE lessons (Jaakkola et al., 2017), and participating in activities that are perceived as gender stereo-typed appeared to have a negative impact on active participation during lessons.

Students also reported that units of work that were repeated frequently across the year was a potential stressor. For example, students reported that some teachers favoured particular sports, which were therefore repeated in the curriculum, resulting in boredom and a lack of interest from the students. Teachers countered this argument, stating that longer units of instruction support skill development and learning, an approach to the curricula which has been supported by previous literature (Ennis, 1999; Kirk, 2004). More recently however research has highlighted the positive effect of a non-traditional curricula, using longer units of instruction of the same content, has on student engagement over time (MacPhail et al., 2008), which may be a consideration for PE practitioners.

\section{Performance environment}

Performance environment was comprised of two higher-order themes: skill acquisition and the public nature of performance activities.

\section{Skill acquisition}


With regard to skill acquisition, students often recalled situations where they found an activity difficult to grasp as a source of frustration, particularly when they continued to try, without success. Teachers similarly recognized that their students would become frustrated if they found the acquisition of a skill difficult: 'We started table tennis... literally the, some of the lads are relatively able, holding their rallies but he [a student] couldn't hit the ball back. And looking around, being in a social setting, he's getting really frustrated' (Teacher B). This teacher highlights the difficulty of grasping particular skills, paired with the social and performance environment of a PE lesson, as a source of frustration for some students. While it may not be feasible for teachers to take a wholly preventative approach to eliminating all potentially frustrating situations in PE, this finding highlights a potential practical implication for teaching practice. Specifically, teachers should aim to respond to the needs of all students, with specific attention to readiness, interest, and abilities (i.e. differentiate lessons; Tomlinson, 1999). For example, teachers may utilize a variety of instructional approaches aimed at modifying content (what students learn), 'support' (how students make sense of content), and the 'product' (how students demonstrate what they have been taught). Previous research in PE has demonstrated that, while PE teachers recognize the value in differentiating in their lessons, they find it particularly challenging to meet the needs of all students (Whipp, 2004). Given the finding of the current study, that many students found situations of unsuccessful skill acquisition as a source of frustration, teachers may prioritize finding ways to use empowering and inclusive techniques that might reduce students' disengagement following poor performance.

Public nature of performance 
Relatedly, PE teachers suggested that PE lessons could be differentiated from classroom-based lessons due to the frequency of public displays of physical skill. The social aspect of performance occurred frequently for students and most students recalled situations whereby their athletic performance was on public display as a potential stressor. Students reported that participating in activities that they felt less competent, or 'rubbish' at, as demanding for them. If not an issue for themselves, students recognized that this may be a potentially threatening stressor for others in their class: 'In the bleep test... If a person's a different size, then they compare themselves to someone else. And might feel uncomfortable or like, they might feel like they're not good enough.' Feelings of shame regarding physical competence were also reported by students when physical sporting ability was made apparent through splitting the class based on ability. A consistent feature (for boys and girls) was to recall being in the top set with pride and responsibility, whilst being in lower sets was associated with a sense of shame and embarrassment:

Philippa, year 10: When we were first here [your set] was a big thing - almost as much as like, Maths, Science and English, so people were like, 'so what set you in for PE?!' and I was like, “well I'm in set three... I don't wanna shout it out". It's nothing to brag about is it? You're in the lowest group.

On the other hand, students from the higher ability groups spoke about their placement in this group with a sense of achievement, and also relief that they did not have to participate with less competent students. These findings resonate with work showing that the construction of physical capital relating to the capacity for successful displays of competence (Hills, 2007; Wiltshire et al., 2017). Poor performances in 
Wiltshire et al's (2017) study were perceived as shame-worthy, resulting in students avoiding exposing themselves through sport to prevent embarrassment. Practitioners may consider approaches to creating a mastery climate during PE lessons, highlighting incremental improvements, and limiting performance-related goals.

\section{Conclusions}

The current study is the first to provide an exploration of the wide range of cumulative stressors that many students experience in PE. There is increasing evidence that daily stressors have a significant impact on academic outcomes, due to their cumulative and proximal nature. For example, adolescents' school-based stressors have been associated with academic performance, wellbeing, and negative attitudes towards school (Byrne et al., 2011; Torres et al., 2012). To date, there has been limited exploration of the common stressors associated with students' participation in PE lessons. The current study identified a range of unique stressors, relating to the social environment, the physical and organisational environment, and the performance environment. Many of the stressors identified in the current study are specific to the context of PE. Therefore, previous findings relating to the experience of daily stressors on educational outcomes cannot be translated to the PE domain and the current study addresses this gap in the literature.

The identification of some of the stressors identified in the current study, including interpersonal transactions between peers, public performance, and body exposure, replicates previous findings (Elliott and Hoyle, 2014; O'Connor and Graber, 2014; Wiltshire et al., 2017; Yli-Piipari et al., 2009). The current study extends previous findings by identifying - potentially frustrating- environmental demands that may 
influence participation. Such environmental demands include discrepancies between individuals' perceived effort levels and those of their peers. Furthermore, the public nature of participating in challenging activities, and the tendency of boasting about physical ability, are examples of the everyday stressors associated with PE that may impact engagement. The research presented here suggests that the stressors experienced in PE are unique from those in the classroom, and thus current findings related to the experience of daily stressors may not be applicable to PE.

\section{Limitations and future directions}

The current study requested PE teachers to select students from their class that reflected a range in terms of their level of ability, motivation and engagement in a PE context. While this may have been achieved, there is a possibility that the sample reflected students who were more likely to respond positively to questions about their experience in PE lessons. Future research may benefit from seeking a random selection of students and complement focus group and interview data with observations of PE lessons. Moreover, the participants in the current study were mainly White British; therefore future research may benefit from exploring the views of individuals from a range of ethnic backgrounds. Furthermore, the current study utilized solely focus groups with students as a means of exploring the experience of common stressors. It is likely that the content students are being taught, and the way in which students are being taught (e.g. performance versus mastery climate) would impact the stressors students experience during their lessons, and the current study does not address these contextual factors. Future research may utilize a mixed method approach (e.g. class observation, ecological momentary assessment, or diaries) which incorporates insights about the curriculum and 
the environmental factors that may influence the experience of stressors to ensure ecological rigour.

The current study has begun to explore common stressors experienced by secondary school students during PE lessons. Future research may progress by investigating differences in the experience and impact of stressors across age groups. Previous research, outside of the PE context, has shown that early adolescents report higher levels of stressors related to health, school, and family. However, as children approach puberty, stressors related to physical changes, romantic attachments, academic demands, and the conflict between leisure and school time, take on greater relevance (Trianes et al., 2012). Further investigations in the PE context may systematically examine the frequency and type of stressors that are experienced by students and whether these differ by age. Furthermore, future research may progress by investigating the cumulative impact of these experiences and investigating how and why some students demonstrate resilience to stressors, while others disengage in the face of the same environmental demands. Although recent years have seen an increased interest in exploring resilience to everyday stressors in school (Martin and Marsh, 2008; Skinner et al., 2013), these investigations refer to general academic challenges. By first identifying common stressors in PE, we can begin to investigate how different students appraise and respond to these stressors, and how this impacts engagement and motivation in PE lessons.

\section{Acknowledgements}

We would like to thank the teachers and students for kindly giving up their time to take part in the current study. 


\section{Disclosure statement}

No potential conflict of interest was reported by the authors. 


\section{References}

Aelterman N, Vansteenkiste M, Van Keer K, et al. (2012) Student's objectively measured physical activity levels and engagement as a function of between-class and betweenstudent differences in motivation toward physical education. Journal of Sport \& Excercise Psychology 34(4): 457-480.

Babic MJ, Morgan PJ, Plotnikoff RC, et al. (2014) Physical activity and physical selfconcept in youth: systematic review and meta-analysis. Sports Medicine 44(11): $1589-1601$.

Band EB and Weisz J (1990) Developmental differences in primary and secondary control coping and adjustment to juvenile diabetes. Journal of Clinical Child \& Adolescent Psychology.

Barrett S and Heubeck BG (2000) Relationships Between School Hassles and Uplifts and Anxiety and Conduct Problems in Grades 3 and 4. Journal of Applied Developmental Psychology 21(5): 537-554.

Bauwens J, Hourcade JJ and Friend M (1989) Cooperative teaching a model for general and special education integration. Remedial and Special Education.

Braun V and Clarke V (2006) Using thematic analysis in psychology. Qualitative Research in Pschology 3(2): 77-101.

Byrne DG, Thomas KA, Burchell JL, et al. (2011) Stressor experience in primary schoolaged children: development of a scale to assess profiles of exposure and effects on psychological well-being. International Journal of Stress Management 18(1): 88111.

Carter JS, Garber J, Ciesla JA, et al. (2006) Modeling relations between hassles and 
internalizing and externalizing symptoms in adolescents: A four-year prospective study. Journal of Abnormal Psychology 115(3): 428-442.

Clarke V and Braun V (2013) Teaching thematic analysis: overcoming challenges and developing strategies for effective learning. The Psychologist 26(2): 120-123.

Cohen S, Kessler RC and Gordon LU (1995) Measuring stress: a guide for health and social scientists. New York: Oxford.

Compas BE (1987) Coping with stress during childhood and adolescence. Psychological Bulletin 101(3): 393-403.

Corder K, Sharp SJ, Atkin AJ, et al. (2015) Change in objectively measured physical activity during the transition to adolescence. British Journal of Sports Medicine 49(11): 730-736.

Elliott D and Hoyle K (2014) An examination of barriers to physical education for Christian and Muslim girls attending comprehensive secondary schools in the UK. European Physical Education Review 20(3): 349-366.

Ennis CD (1999) Creating a culturally relevant curriculum for disengaged girls. Sport, Education and Society 4: 31-49.

Ennis CD and Chen S (2012) Interviews and focus groups. In: Armour K and MacDonald D (eds), Research Methods in Physical Education and Youth Sport, New York: Routledge, pp. 217-236.

Escobar M, Alarcón R, Blanca MJ, et al. (2013) Daily stressors in school-age children: a multilevel approach. School Psychology Quarterly 28(3): 227-238. Available from: http://doi.apa.org/getdoi.cfm?doi=10.1037/spq0000020.

Evans GW (2006) Child development and the physical environment. Annual Review of 
Psychology 57: 423-451.

Fairclough S (2003) Physical activity, perceived competence and enjoyment during high school physical education. European Journal of Physical Education 8(1): 5-18.

Flintoff A and Scraton S (2001) Stepping into active leisure? Young women's perceptions of active lifestyles and their experiences of school physical education. Sport, Education and Society 6(1): 5-21.

Fox KR and Edmunds LD (2000) Understanding the world of the“ fat kid': can schools help provide a better experience? Reclaiming Children and Youth 9(3): 177.

Grannis JC (1992) Students' stress, distress, and achievement in an urban intermediate school. Journal of Early Adolescence 12(1): 4-27.

Grástén A (2016) Testing the model of motivational climate, goal orientations, expectancy beliefs, task values in school physical education, and associated links to light- to vigorous-intensity physical activity. International Journal of Sports Psychology 47(5): 408-427.

Guba EG (1990) The Paradigm Dialogue. Newbury Park, CA: Sage.

Heubeck B and O'Sullivan C (1998) An exploration into the nature, frequency and impact of school hassles in the middle school years. Australian Psychologist 33(2): $130-137$.

Hills L (2007) Friendship, physicality, and physical education: an exploration of the social and embodied dynamics of girls' physical education experiences. Sport, Education and Society 12(3): 317-336.

Hollis JL, Sutherland R, Williams AJ, et al. (2017) A systematic review and metaanalysis of moderate-to-vigorous physical activity levels in secondary school 
physical education lessons. International Journal of Behavioral Nutrition and Physical Activity 14(1).

Jaakkola T, Yli-Piipari S, Barkoukis V, et al. (2017) Relationships among perceived motivational climate, motivational regulations, enjoyment, and PA participation among Finnish physical education students. International Journal of Sport and Exercise Psychology, 15(3): 273-290.

Kanner AD, Coyne JC, Schaefer C, et al. (1981) Comparison of two modes of stress measurement: daily hassles and uplifts versus major life events. Journal of Behavioral Medicine 4(1): 1-39.

Kanner AD, Feldmen SS, Weinberger DA, et al. (1987) Uplifts, hassles, and adaptational outcomes in early adolescents. Journal of Early Adolescence 7(4): 371-394.

Kearney CA, Drabman RS and Beasley JF (1993) The trials of childhood: The development, reliability, and validity of the daily life stressors scale. Journal of Child and Family Studies 2(4): 371-388.

Kiang L and Buchman C (2014) Daily stress and emotional well-being among Asian American adolescents: Same-day, lagged, and chronic associations. Developmental Psychology 50(2): 611.

Kirk D (2004) Framing quality physical education: the elite sport model or sport education? Physical Education and Sport Pedagogy 9: 185-195.

Kohl HW, Craig CL, Lambert EV, et al. (2012) The pandemic of physical inactivity: global action for public health. The Lancet, Elsevier Ltd 380(9838): 294-305.

Kraag G, Zeegers MP, Kok G, et al. (2006) School programs targeting Stress management in children and adolescents: a meta-analysis. Journal of School 
Psychology 44(6): 449-472.

Lazarus RS (1984) Puzzles in the study of daily hassles. Journal of Behavioral Medicine 7(4): 375-389.

Lazarus RS and Eriksen C (1952) Effects of failure stress upon skills performance. Journal of Experimental Psychology 43(2): 100-105.

Lazarus RS and Folkman S (1984) Stress, appraisal and coping. In: New York: Springer.

Lazarus RS and Launier R (1978) Stress- related transactions between person and environment. In: Pervin L and Lewis M (eds), Perspectives in Interactional Psychology, Boston, MA: Springer. pp.287-327.

Lehman B and Repetti RL (2007) Bad days don't end when the school bell rings: the lingering effects of negative school events on children's mood, self-esteem, and perceptions of parent-child interaction. Social Development 16(3): 1-23.

Lincoln YS and Guba EG (1985) Naturalistic Inquiry. Newbury Park, CA: Sage.

Liston C, Watts R, Tottenham N, et al. (2006) Frontostriatal microstructure modulates efficient recruitment of cognitive control. Cerebral Cortex 16(4): 553-560.

Lonsdale C, Rosenkranz RR, Peralta LR, et al. (2013) A systematic review and metaanalysis of interventions designed to increase moderate-to-vigorous physical activity in school physical education lessons. Preventive Medicine 56(2): 152-161.

MacPhail A, Gorely T, Kirk D, et al. (2008) Children's experiences of fun and enjoyment during a season of sport education. Research Quarterly for Exercise and Sport 79(3): 344-355.

Martin AJ (2013) Academic buoyancy and academic resilience: Exploring 'everyday' and 'classic' resilience in the face of academic adversity. School Psychology 
International 34(5): 488-500.

Martin AJ and Marsh HW (2008) Academic buoyancy: Towards an understanding of students' everyday academic resilience. Journal of School Psychology 46(1): 53-83. McNamara S (2000) Stress in young people: What's new and what can we do? London: Continuum International Publishing Group.

Mitchell F, Gray S and Inchley J (2013) 'This choice thing really works ...' Changes in experiences and engagement of adolescent girls in physical education classes, during a school-based physical activity programme. Physical Education \& Sport Pedagogy 20(6): 1-19.

Morse JM (2003) A review committee's guide for evaluating qualitative proposals. Qualitative Health Research 13: 833-851.

O'Connor JA and Graber KC (2014) Sixth-grade physical education: an acculturation of bullying and fear. Research Quarterly for Exercise and Sport 85(3): 398-408.

O’Donovan G, Blazevich AJ, Boreham C, et al. (2010) The ABC of physical activity for health: A consensus statement from the British association of sport and exercise sciences. Journal of Sports Sciences 28(6): 573-591.

O’Reilly M and Parker N (2013) 'Unsatisfactory saturation': A critical exploration of the notion of saturated sample sizes in qualitative research. Qualitative Research 13(2): 190-197.

Paechter C (2003) Power, bodies and identity: how different forms of physical education construct varying masculinities and femininities in secondary schools. Sex Education 3(1): 47-59.

Rahdar A and Galvan A (2014) The Cognitive and Neurobiological Effects of Daily 
Stress in Adolescents. Neuroimage 92: 267-273.

Ridgers ND, Fazey DMA and Fairclough SJ (2007) Perceptions of athletic competence and fear of negative evaluation during physical education. British Journal of Educational Psychology 77(2): 339-349.

Sandstrom MJ, College W and Cillessen AHN (2003) Children's appraisal of peer rejection experiences : Impact on social and emotional adjustment. Social Development 12(4): 530-545.

Schwandt TA (1998) Constructivist, interprestivist approaches to human enquiry. Handbook of Qualitative Research 1: 118-137.

Serido J, Almeida DM and Wethington E (2004) Chronic stressors and daily hassles: Unique and interactive relationships with psychological distress. Journal of Health and Social Behavior 45(1): 17-33.

Sim H (2000) Relationship of daily hassles and social support to depression and antisocial behavior among early adolescents. Journal of Youth and Adolescence 29(6): 647-659.

Skinner E, Pitzer J and Steele J (2013) Coping as part of motivational resilience in school: a multidimensional measure of families, allocations, and profiles of academic coping. Educational and Psychological Measurement 73(5): 803-835.

Smith JA (2007) Qualitative Psychology: A Practical Guide to Research Methods. In: London: Sage.

Sotardi VA (2017) Exploring school stress in middle childhood: interpretations, experiences, and coping. Pastoral Care in Education, Routledge 35(1): 13-27. Standage M, Duda JL and Ntoumanis N (2005) A test of self-determination theory in 
school physical education. British Journal of Educational Psychology 75(3): 411433.

Tomlinson CA (1999) Educational leadership: personalized learning: mapping a route toward differentiated instruction. Educational Leadership 57(1): 12-16.

Torres MVT, Mena MJB, Fernandez-Baena FJ, et al. (2012) Assessment and treatment of daily stress in childhood. Evaluacion y tratamiento del estres cotidiano en la infancia. 33(1): 30-35.

Whipp P (2004) Differentiation in outcomes focused physical education: pedagogical rhetoric and reality. Australian Association for Research in Education: 1-17.

Williamson DE, Birmaher B, Ryan ND, et al. (2003) The Stressful Life Events Schedule for children and adolescents: Development and validation. Psychiatry Research 119(3): 225-241.

Wiltshire G, Lee J and Evans J (2017) 'You don't want to stand out as the bigger one': exploring how PE and school sport participation is influenced by pupils and their peers. Physical Education and Sport Pedagogy 22(5): 1-14.

Yli-Piipari S, Watt A, Jaakkola T, et al. (2009) Relationships between physical education students' motivational profiles, enjoyment, state anxiety, and self-reported physical activity. Journal of Sports Science \& Medicine 8(3): 327-336. 


\begin{tabular}{|c|c|c|c|}
\hline Raw Data Quotes & $\begin{array}{l}\text { First Order } \\
\text { Themes }\end{array}$ & $\begin{array}{l}\text { Second } \\
\text { Order } \\
\text { Themes }\end{array}$ & $\begin{array}{c}\text { General } \\
\text { Dimensions }\end{array}$ \\
\hline $\begin{array}{l}\text { Liam, year eight: Working in a team with people that I don't get on with tends to be quite } \\
\text { hard. Well, erm... I would... in the past I've fallen out with some of my friends and then erm, } \\
\text { we were put in a group together so I had to work with him and it was really awkward. So I } \\
\text { struggled with that quite a bit. } \\
\text { Boys, year seven. [when discussing body image] } \\
\text { Vinnie: - some people might feel awkward. Sometimes like, when you're getting changed... } \\
\text { you can be getting changed like, with the boys a-and if someone a bit overweight then people } \\
\text { take the mick out of them, and then net time they try and... hide behind from the people who's } \\
\text { takin the mickey out of them... and then they feel sad when they do PE which is... not good... } \\
\text { Dillon: - well we don't exactly take the mick out of them, but like... we won't say it to their } \\
\text { faces...no- no one's said it to their faces... but we do probably say it behind their back... } \\
\text { James, year nine: Some people ain't got the right mindset with things, like, they just do what } \\
\text { they want and like, stand at the back, like during football, just stand at the back talking to their } \\
\text { mates, thinking it's a doss lesson. Bu they need to put the work in... } \\
\text { Mark, year nine: Yeah we just let them get on with it. We're not gunna stoop to their level. } \\
\text { Mia, year 10: When we got put into sets, when people said, 'What set are you in?' and you'd } \\
\text { say, 'Set Three', they'd be like, 'well, you're not fit then, you should be in Set Two' or they'd } \\
\text { brag about being in Set One and it'd get you down. }\end{array}$ & $\begin{array}{c}\text { Negative } \\
\text { comments } \\
\text { Differences in } \\
\text { participation } \\
\text { Boasting between } \\
\text { peers }\end{array}$ & Peers & 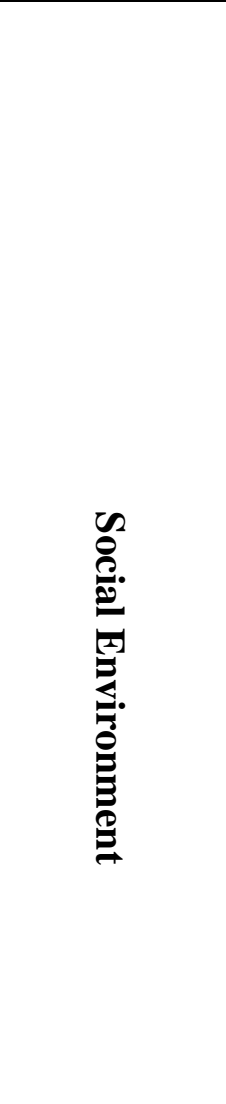 \\
\hline $\begin{array}{l}\text { Year } 10 \text { boys. Louis: Another one is Mr. A. You really can't have a joke with him. Like, he'll } \\
\text { always take it so seriously. Mark: It's as if he's in the army, everything's like, military style and } \\
\text { I think like, you have to enjoy it as well ain't you? }\end{array}$ & Teacher is strict & Teachers & \\
\hline
\end{tabular}


Lucy, year 10: There's a few girls here that enjoy sport but they're very conscious of the kit that they wear and who's watching and if there's a boy group nearby. And it's a shame because I don't think they work as hard because they're too conscious about what they look like in their PE kit.

Sarah, year 10: It's when you're trying your hardest, but then the teachers tell you to work harder and don't appreciate that that is your hardest.

Teacher A. Just getting changed it a massive issue for some of our pupils... I probably have about five or six boys that go into the staff changing rooms... we've had boys that, in terms of swimmin' that have got changed in a cubicle because of having one testicle or a concave chest or... just bein' obese.

Girls, year 10 [discussing availability of activities]

Charlotte, year 10: Some sports just aren't available for girls. Like football, rugby... Which, sometimes people may enjoy those sports more than the normal girl's ones like netball.

Andrea, year 10: but then there's one's that boys can't access like gymnastics and stuff like that -

Mia year 10: I find that unfair because even with trampolining, the boys were doing front flips and back flips but we were just doing seat drops, and we asked the teacher if we could try, 'cause I've done it before at home, and she just said 'no'.

Claire, year eight: Yeah 'cause we just do the same things with Miss E all the time. It's like netball and netball, hockey, netball, hockey, hockey, netball, and I just get bored.

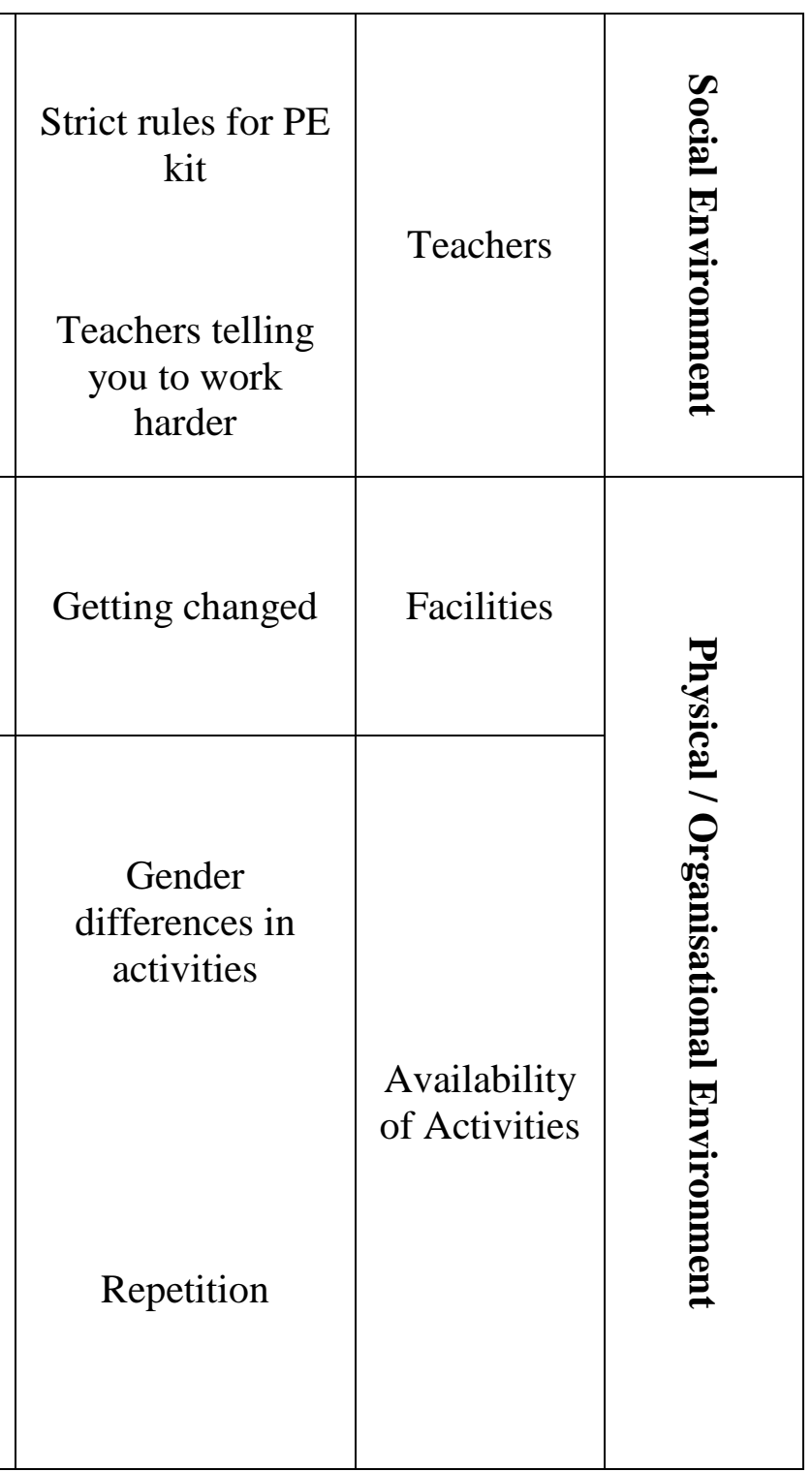


Will, year nine: In PE, I find difficult, long distance running... Just after a while... My legs... I just find it difficult... and, well on sports days... I didn't sign up for anything... so I had to do the $800 \mathrm{~m}$ and I wasn't very good at it and I really didn't want to go.

Beth, year eight: - cause when you can't do somethin' and they tell you to do it and you can't do it, it makes you angry. I: Yeah. And what kind of things? B: Once when I did hockey last year and they made me do it and I felt a bit down and that and Miss was like, 'keep trying, keep trying', but I couldn't do it. So it was making me angry and then I wasn't happy for the whole day 'cause it had made me feel down.

Gemma, year eight: I think there's some people that are quite like, conscious about their appearance and I think that like affects them. Cause if sometimes people are bit bigger than sometimes you're a bit conscious and I feel like that kind of stops you from getting involved. And they think, 'oh what if they're saying stuff about me?'

Amy, year seven: ... if you do basketball and you're the shooter and it doesn't go in. It's hard then to like... get your confidence back to try again and you think the team's gunna think you're like... rubbish.

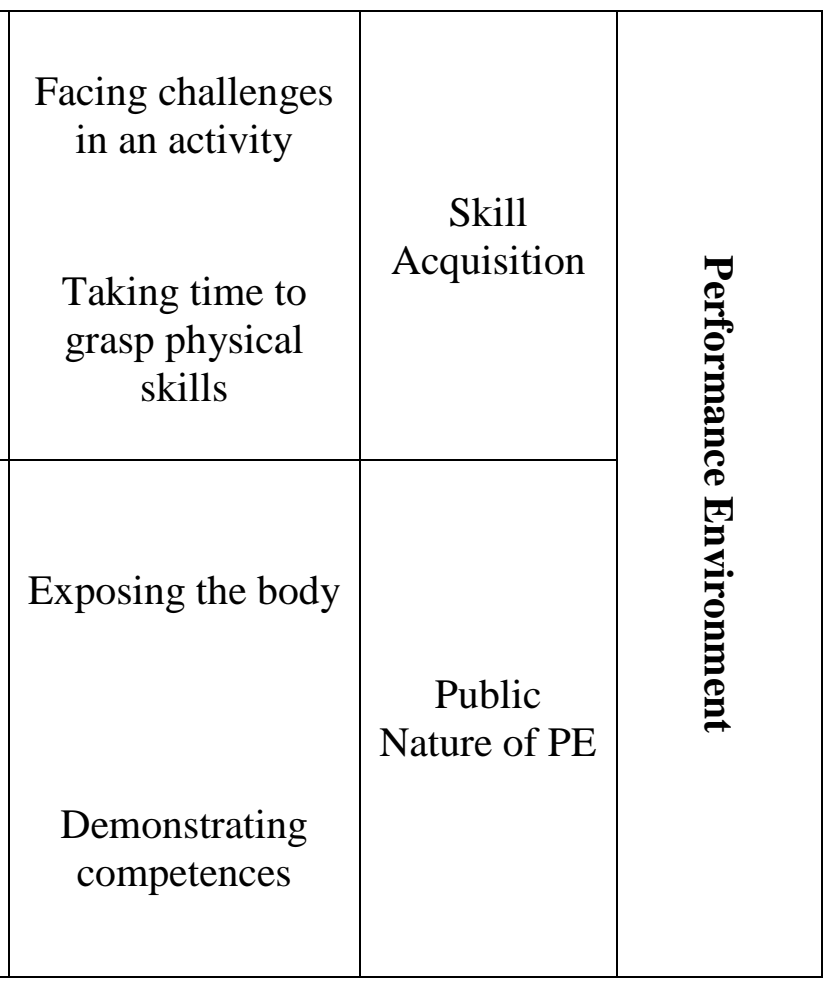

